\title{
Physical and numerical modeling of canal lining on expansive soil
}

\author{
M.Hajialilue-Bonab ${ }^{\text {i) }}$ and F.Behrooz-Sarand ${ }^{\text {ii) }}$
}

i) Associate Professor, Department of Civil Engineering, University of Tabriz, 29 Bahman Street, Tabriz, Iran.

ii) Assistant Professor, Department of civil engineering, Tabriz Branch, Islamic Azad University, Tabriz, Iran.

\begin{abstract}
The volume of expansive soil is varied when its moisture condition is changed. The results of these soil volume variation are led to cracking or uplift in light structures. One type of these vital structures is water-conveyance-lining canals. The damage of these canals impose heavy cost on irrigation and drainage network projects. In this paper two ways are studied to control and reduce the effect of swelling soil on canal lining. The first way is the optimization of number of joints on canal lining and the second is the study of location of joints on soil-lining interaction behavior. These proposed approaches have been evaluated with two methods: physical and numerical modeling. The irrigation and drainage network of Tabriz plain canal that is under construction on expansive soil is selected as a case study in this paper. The physical models are constructed as small scale (1/10) in laboratory. Also SIGMA/W 2007 software which is one of the programs in Geo-Studio software package is used for numerical modeling. The results of physical and numerical modeling show the effect of joints to control and distribute of expansive soil-canal lining interaction forces. It can be inferred from results, the relative displacement of panels and destructive bending moments of lining are decreased by considering joints on location of maximum internal forces in the canal section. The number and arrangement of joints should be chosen based on canal section characteristics such as geometric properties and swelling potential of bed soil. Based on obtained results for current condition, considering two series of joints are recommended in both of the canal section walls, first series near the canal floor, the intersection point of wall and floor, and second series about middle height of canal section, the concentration point of interaction forces.
\end{abstract}

Keywords: expansive soil, canal, physical modeling, numerical modeling, joint.

\section{INTRODUCTION}

One of the most common types of problematic soils is expansive soils. Expansive soils are a worldwide challenge. They pose problems for civil engineering in general and for geotechnical engineering in particular (Chen, 1988). Such soils cause damage to structures founded on them because of their potential to react to change in moisture. They undergo severe volume changes corresponding to change in moisture content. Expansive soils swell or increase in their volume when they imbibe water and shrink or reduce in their volume because of water evaporation (Chen, 1988; Sharma, 1998; Rao et al., 2004). The damage in the hydraulic canals which constructed on expansive soils are observed in the forms of cracking in the concrete lining and their uplift. Over time and with the occurring of thaw and freezing cycles, lining fine micro cracks are become larger and provide a situation for water penetration and plant growth. These factors eventually lead to change of hydraulic canal characteristics and finally its destruction.
Physical modeling has an important role in geotechnical studies in recent years. But the study of interaction behavior between expansive soil and light structure with physical modeling is a subject that received less attention than other infrastructure issues. The behavior of slopes and tunneling in expansive soils are important issues that were studied with physical modeling over the years.

As numerical studies view point, the behavior of expansive soil can be formulated using the theory of unsaturated soils, formulated using two independent stress variables, the constitutive relationships for the soil structure and water phase and flow laws for the water phase (Fredlund and Raharadjo, 1993, Vu and Fredlund, 2004).

The aim of this paper is to study and discuss the effect of expansive soil on canal structure by physical and numerical modeling. Also, it is attempted to suggest some ways to control and reduce the effect of soil swelling on canal lining damage. For this purpose, Tabriz plain canal is selected as a case study and the geometric properties and joint locations of physical 
models are selected based on its characteristics with considering small scale relations $(1 / 10)$.

The irrigation and drainage network of Tabriz plain is under construction on expansive soil in the northwestern part of Iran. The length of the main canal is $29 \mathrm{~km}$, width of floor between 2.5 to $5.0 \mathrm{~m}$, and its height between 2 to $2.75 \mathrm{~m}$. The slope of canal walls is 1 (vertical) to 1.5 (horizontal). The canal lining is made of unreinforced concrete. Three series of joints are considered in the canal section: two joints in canal walls in the level of 0.5 meter from the floor and one joint in center line of canal floor (Hajialilue-Bonab et al., 2009). It should be noted that these joints were not filled with mastic or any other.

After construction first $10 \mathrm{~km}$ of canal path, some parts of canal in this distance were filled with water. After the water was emptied out, cracks and heave were observed in parts of the canals. It seems that the water in canal penetrated from joints into the lean concrete. Since this type of concrete is porous material and water could seep in the bed soil and led to change of its moisture content and this variation of soil wetting caused the swelling phenomenon.

\section{PHYSICAL MODELING}

In this part of paper, the physical models that are planned to study the interaction behavior between expansive soil and canal lining is explained.

\subsection{Experimental setup}

In current study four tests are planned and performed to achieve the desired objectives. The more details of these tests are presented later. Some basic information about construction of physical models is briefly explained here. These are about soil sample preparation, test box, cutting and shaping of model, instrumentation of lining and so on.

As discussed before in this research, Tabriz plain canal is considered as the case study. Therefore the dimensions of test box are selected based on this canal characteristics by considering small scale requirements.

As shown in Figure 1, the test apparatus consists of a bottom box (i), a top extension (ii), a lid (rigid plate)(iii) and two Perspex sheets. The bottom box, the principle part of the test apparatus where the canal is constructed, has a rectangular shape with open side faces. It has $1050 \mathrm{~mm}$ length, $200 \mathrm{~mm}$ width and 450 $\mathrm{mm}$ height (this height is doubled when the top-extension is added). The lateral sides of bottom box are equipped with eight $10 \mathrm{~mm}$ diameter holes with valves for allowing drainage during consolidation. The top-extension provides sufficient height to accommodate the unconsolidated clay slurry.

This slurry is constructed in specific mixer and then moved to this test box. $30 \mathrm{~mm}$ thickness clear Perspex windows are fitted into the open side faces enabling observation of the soil movements. The lid, to which the jack is attached, has two holes with valves for drainage. The consolidation pressure is applied via one hydraulic jack positioned at central point of lid.

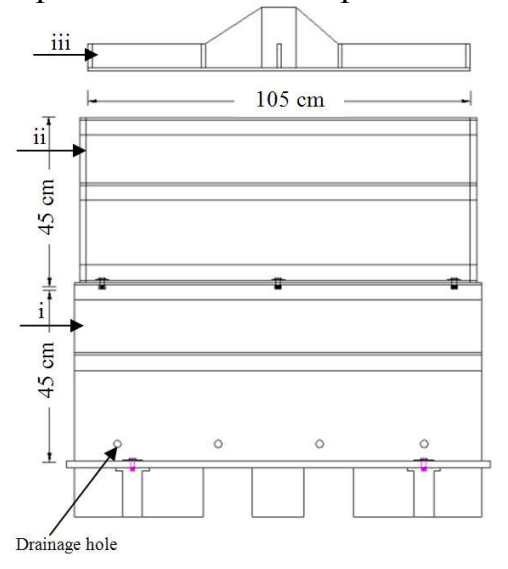

Fig 1. Configuration the laboratory test box

In tests, Bentonite and Kaolin are selected for preparing the slurry. Several laboratory tests are done to select the percentage of these soils in sample mixture. Some of these initial tests are included gradation, Atterberg limits, Specific gravity and swelling consolidation tests. Based on the results of these tests, in first step, the weight mixture of $30 \%$ Bentonite and $70 \%$ Kaolin is selected to prepare the slurry (Test 1). This mixture is became to $20 \%$ Bentonite and $80 \%$ Kaolin in Tests 2, 3 and 4 based on obtained results from Test 1 .

The clay slurry then moved from mixer to test box and consolidated using the hydraulic jack. It takes approximately 108 days to complete the consolidation of model sample in Test1. The consolidation pressure is applied using loading stages of 4,12,25,50,100, $200 \mathrm{kPa}$ respectively.

After the completion of primary consolidation in final loading process, the unloading process is started. Before the unloading stage from $200 \mathrm{kPa}$ to zero is performed, the sample is isolated from potential sources of water which could permit elastic swelling, the bottom drainage layer is closed and any free water on the top surface of clay is removed (Take, 2003). As this final unloading proceeded, therefore, the clay is subjected to an initial suction approximately $200 \mathrm{kPa}$ same as in situ condition.

For monitoring the behavior of canal lining and calculation of bending moment, eight strain gauges are considered on Aluminum sheet as shown in Figure 2. In addition, holes with $2 \mathrm{~mm}$ diameter and $5 \mathrm{~cm}$ distance are performed on this sheet (See Figure 2). Water can leak through these holes and joints to bed soil of model. The pores between Aluminum sheet and side walls of tank is isolated by silicon grease. The weight of lining is also applied on model by special surcharge. This surcharge is made of fixed metal balls that applied uniform stress about $0.2 \mathrm{kPa}$ on model. 


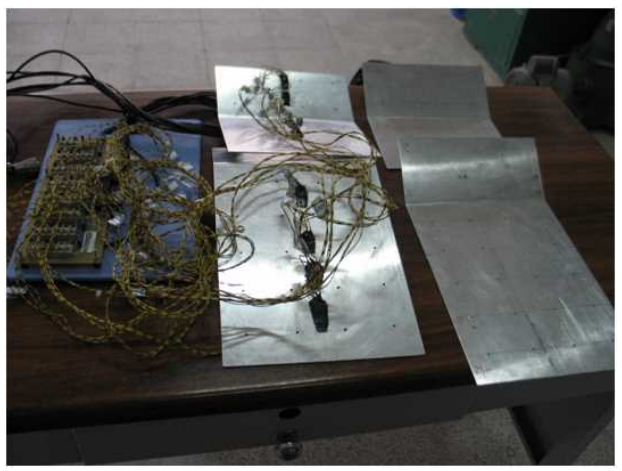

Fig 2. Instrumentation of lining model

The deformation measurement system based on particle image velocimetry (PIV) and close-range photogrametry has been developed for use in geotechnical testing by white et al. (White et al., 2003).In this study, a Canon G10 (14.7 megapixel) camera facilitated visualisation of the soil movement during test and image processing. Two special projectors positioned on both sides of the camera at $45^{\circ}$ angles and one positioned above the camera's optical axis eliminated optical effects from the environment on the viewing window, avoiding errors caused by random variation in pixel intensity. In all of tests, the amount of soil displacement has been recorded during the 16 days after the canal impounding. The deformation rate of soil samples is negligible after this period .During the tests, the level of water in canal is kept constant and $15 \mathrm{~cm}$ above the canal floor.

\subsection{Physical tests program}

As mentioned before, in this paper three tests are performed to study the effect of joints on interaction behavior of expansive soil and canal lining. The main specifications of these tests are explained in table 1. In this table, B, K, H and V express Bentonite, Kaolin, Horizontal and vertical directions, respectively.

\begin{tabular}{cccc} 
Table 1. & Specifications of tests \\
\hline $\begin{array}{c}\text { Test } \\
\text { Number }\end{array}$ & $\begin{array}{c}\text { Mixture of } \\
\text { soil sample }\end{array}$ & $\begin{array}{c}\text { Slope of the } \\
\text { canal walls }\end{array}$ & $\begin{array}{c}\text { Number } \\
\text { of joints } \\
\text { on wall }\end{array}$ \\
\hline Test1 & $30 \% \mathrm{~B}+70 \% \mathrm{~K}$ & $1.5 \mathrm{H}: 1 \mathrm{~V}$ & 1 \\
\hline Test2 & $20 \% \mathrm{~B}+80 \% \mathrm{~K}$ & $1.5 \mathrm{H}: 1 \mathrm{~V}$ & 1 \\
\hline Test3 & $20 \% \mathrm{~B}+80 \% \mathrm{~K}$ & $1.5 \mathrm{H}: 1 \mathrm{~V}$ & 2 \\
\hline
\end{tabular}

In table2 and Figure3, the installation positions of strain gauges in any of tests are given.

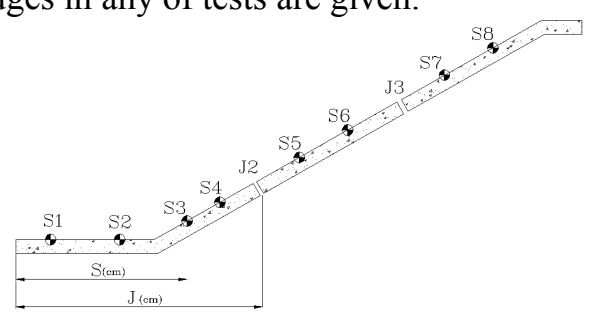

Table 2. Location of joints and strain gauges in lining models

\begin{tabular}{|c|c|c|c|c|c|c|c|c|c|c|}
\hline \multirow{2}{*}{$\begin{array}{l}\text { Test } \\
\mathrm{N} .\end{array}$} & \multicolumn{2}{|c|}{$\begin{array}{c}\text { Joint } \\
\text { locations } \\
(\mathrm{J}: \mathrm{cm})\end{array}$} & \multicolumn{8}{|c|}{ Strain gauge locations $(\mathrm{S}: \mathrm{cm})$} \\
\hline & $\mathrm{J}_{2}$ & $\mathrm{~J}_{3}$ & $\mathrm{~S}_{1}$ & $\mathrm{~S}_{2}$ & $\mathrm{~S}_{3}$ & $\mathrm{~S}_{4}$ & $\mathrm{~S}_{5}$ & $\mathrm{~S}_{6}$ & $\mathrm{~S}_{7}$ & $\mathrm{~S}_{8}$ \\
\hline 1 & 20 & - & \multirow[b]{2}{*}{3.1} & \multirow[b]{2}{*}{9.4} & \multirow[b]{2}{*}{15} & \multirow[b]{2}{*}{17.5} & \multirow[b]{2}{*}{24.3} & \multirow[b]{2}{*}{28.2} & \multirow[b]{2}{*}{32.8} & \multirow[b]{2}{*}{38.4} \\
\hline $\begin{array}{l}2 \\
3\end{array}$ & 20 & 31.25 & & & & & & & & \\
\hline
\end{tabular}

\section{NUMERICAL MODELING}

In this research, SIGMA/W 2007 software is used for numerical modeling. The basis of this software for modeling of unsaturated expansive soils is the behavioral model and presented equations by Hung et al. (2006). It should be noted that the input parameters of the software and the solution of the equations are simplified as much as possible toward the method $\mathrm{Vu}$ and Fredlund (Hung et al., 2006) to be applicable for geotechnical engineers (GEO-SLOPE, 2008). Thus, SIGMA/W software can be used to estimate the amount of swelling in unsaturated expansive soils that are affected by changes in wetting conditions and consequent negative pore pressures.

In this paper, Tests 2, 3 and 4 are also studied by numerical modeling. So the geometric properties of physical models are used for numerical modeling. In numerical studies as a test condition, for modeling of joints, $2 \mathrm{~mm}$ space is vertically considered in lining surface. The arrangement of them on model is selected based on physical test conditions. Mixed quad and triangle unstructured mesh is used in constructed models. In addition the lining has been modeled using beam elements.

For simulation of the initial conditions (local conditions), it has been assumed that the canal bed soil is somewhat dried and a constant suction is established in the soil. Generally, it is assumed that in the initial conditions, a suction equal to $200 \mathrm{kPa}$ is available in the environment. This suction is also applied to physical models by reloading of jack pressure. For modeling the infiltration into the soil, water level inside the canal is applied as a water head to the lining elements. In all models, appropriate boundary conditions are applied. For this purpose, lateral sides and bottom of models are constrained from horizontal and vertical displacements, respectively.

Some required parameters for numerical analysis are presented in Table 3. The most of these parameters are obtained from laboratory tests results. In table $3, \gamma$, $\Phi, \mathrm{C}, \mu, \mathrm{E}, \mathrm{e}, \mathrm{I}$ and $\mathrm{k}$ are, respectively, unit weight, friction angle, adhesion coefficient, Poisson's ratio, modulus of elasticity, void ratio, moment of inetia and permeability coefficient.

Fig 3. Schematic position of Joints and Strain gauges 
Table 3. Input data for numerical modeling (Tests 2, 3 and 4)

\begin{tabular}{ccccccc}
\hline \multicolumn{7}{c}{ Expansive soil of canal bed } \\
\hline $\begin{array}{c}\gamma \\
\left(\mathrm{kN} / \mathrm{m}^{3}\right)\end{array}$ & $\Phi$ & $\begin{array}{c}\mathrm{C} \\
\left(\mathrm{kN} / \mathrm{m}^{2}\right)\end{array}$ & $\mu$ & $\begin{array}{c}\mathrm{E} 0 \\
\left(\mathrm{kN} / \mathrm{m}^{2}\right)\end{array}$ & $\begin{array}{c}\mathrm{ksat} \\
(\mathrm{cm} / \mathrm{s})\end{array}$ & $\mathrm{e}_{0}$ \\
\hline 16 & 20 & 20 & 0.4 & 3000 & $10^{-6}$ & 1.21 \\
\hline \multicolumn{7}{c}{ Lining } \\
\hline $\begin{array}{c}\gamma \\
\left(\mathrm{kN} / \mathrm{m}^{3}\right)\end{array}$ & $\mu$ & $\begin{array}{c}\mathrm{E} \\
\left(\mathrm{kN} / \mathrm{m}^{2}\right)\end{array}$ & $\begin{array}{c}\mathrm{I} \\
\left(\mathrm{m}^{4}\right)\end{array}$ \\
\hline 21 & & 0.2 & $2.3 \times 10^{7}$ & $3.25 \times 10^{-8}$ \\
\hline
\end{tabular}

\section{RESULTS AND DISCUSSION}

The obtained results of Test 1 are extensively explained in this paper whilst the results of other tests are generally presented in continue. In addition, Tests 2 , 3 and 4 are also studied numerically and the results of physical and numerical methods are compared.

\subsection{Test 1}

The constructed physical model for Test 1 are shown in Figures 4.

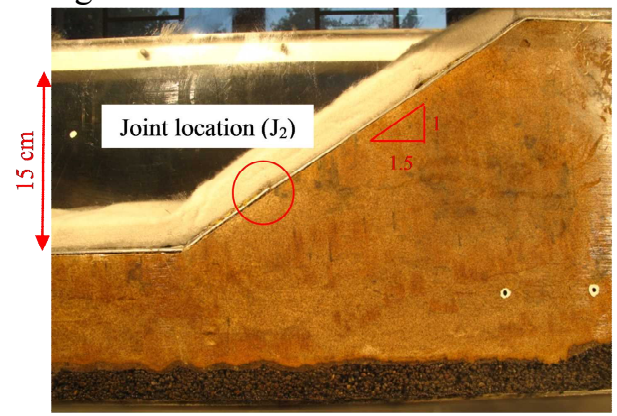

Fig 4. Physical model of Test1

In Figure5, the vertical displacement contours of soil in Test 1that obtained from PIV method is shown. By referring to Figure 5, it can be seen that the amount of soil swelling in canal surface and just under the lining is greater than other points. The magnitude of displacement vectors in the base of model is very low. Increasing the weight of soil mass and decreasing the variation of soil moisture content in the depth of canal section can lead to reducing the soil swelling in this level. The maximum value of soil swelling is approximately seen in middle height of canal section and equal to $9.5 \mathrm{~mm}$ in this model. It shows that the middle point of canal section height is a critical point and the maximum value of interaction force between expansive soil and lining is occurred in this position. In addition, the concentration of displacement contours around joint location is clearly seen in Figure5. This phenomenon can be expressed by the relative displacement of panels in two sides of joints in canal walls. Another issue that can be discussed in Figure 5 is the different values of heave between floor and wall. The maximum value of floor heave is about $4.0 \mathrm{~mm}$ and this value is reduced by increasing of depth. At the base of the model, the heave value is recorded $0.0 \mathrm{~mm}$. This value represents that the height of the model is selected appropriately based on active zone concept.

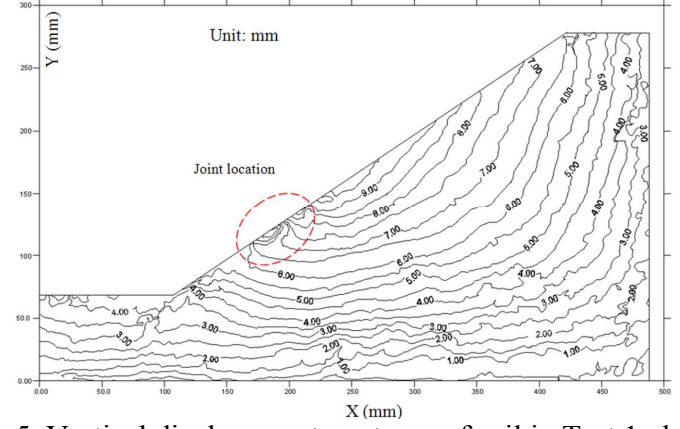

Fig 5. Vertical displacement contours of soil in Test 1 obtained from PIV method

The volumetric and shear strain contours of soil are shown in Figures 6 and 7, respectively. These contours are calculated and drawn using obtained data from PIV method, too. As seen in these figures, the maximum values of volumetric and shear strain in Test 1 were obtained $6.5 \%$ and $0.3 \%$. As expected, increasing in volume of model is larger than its deformation. In both of these figures, the concentration of strain contours occurs about middle height of canal wall. So this point can be regarded as a critical point at which the interaction force reaches its maximum value.

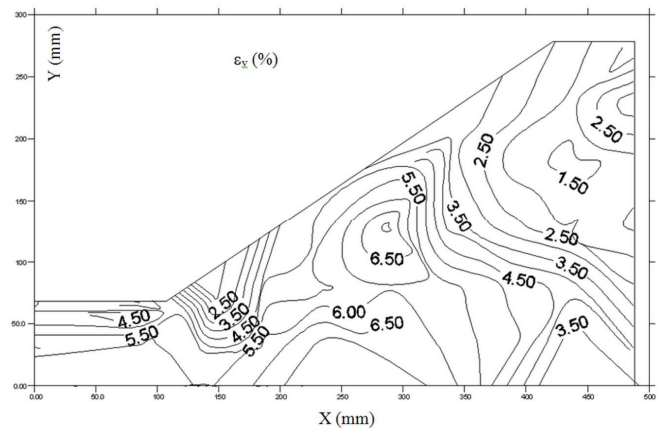

Fig 6. Volumetric strain contours of soil in Test

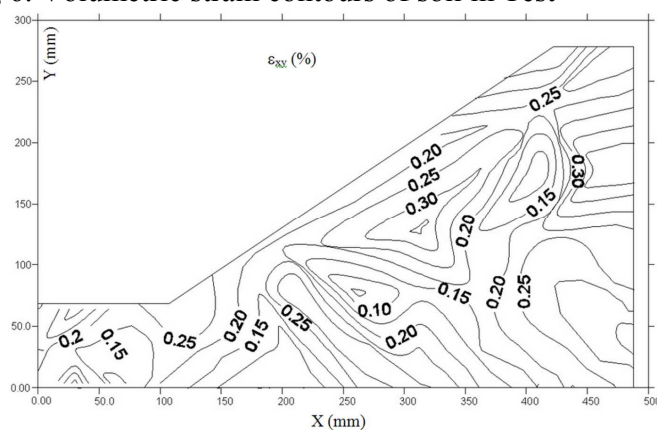

Fig 7. Shear strain contours of soil in Test 1

It is concluded that in Test 1 , the values of soil swelling and strains is too much for the current scale of modeling and this value of heave cannot be happen in site. On the other hand, the required time for preparing of such soil sample is very long. To solve these problems, it is decided to modify the mixture of model samples in subsequent tests. So in Tests 2, 3 and 4, the percentage of Bentonite weight is reduced to $20 \%$. This change is led to reducing the consolidation time from 108 days to 80 days. Because of the all mentioned reasons, Test 1 is not modelled numerically in this paper. 


\subsection{Test 2}

The maximum value of swelling in this test is recorded about $4.5 \mathrm{~mm}$. It can be seen that the amount of swelling is approximately halved compared with the first test. This result emphasizes on the effect of active clay mineral presence such as Bentonite on soil mass heave. By considering these differences between the results of Tests 1 and 2, it is inferred that the behavior mechanism of samples are similar in two tests. These similarities include the location of maximum displacement, the general shape of contours, concentration points of contours and so on. It is also an emphasis on the accuracy of the tests. Based on the obtained results, the relative displacement of panels in canal wall reduced from $0.6 \mathrm{~mm}$ to $0.35 \mathrm{~mm}$ in Test 2 . It indicates that this parameter is strongly decreased when the swelling potential of bed soil is reduced.

In continue, some results obtained from numerical modeling of Test 2 are given.

The vertical displacement contours that obtained from numerical modeling of Test 2 are also shown in Figure 8. By comparing this figure with results of physical modeling, it can be inferred that the general shape of counters are exactly same in these figures. It is indicated that the numerical model is reasonably able to predict the deformation shape and displacement magnitude of soil and lining.

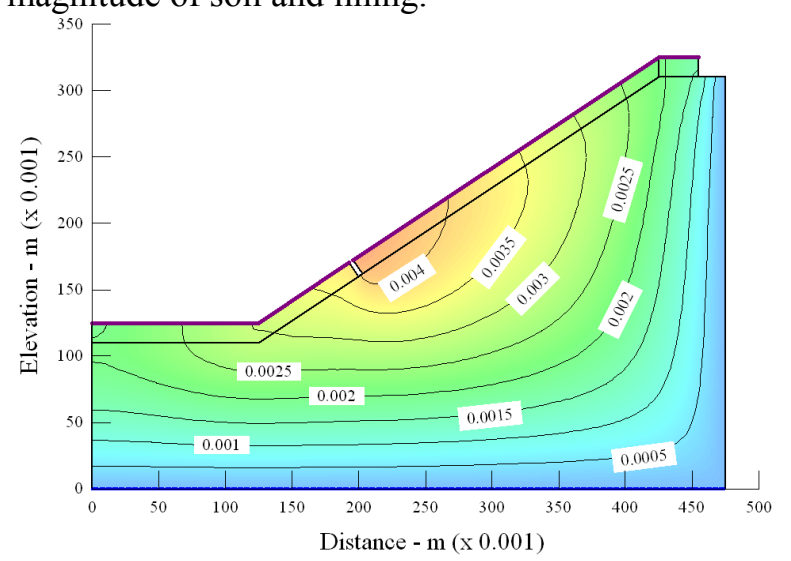

Fig 8. Vertical displacement counters in Test 2 obtained from numerical modelling

In Figure 9 and for Test 2, the occurred moment of concrete lining that are calculated by numerical model and also obtained from monitoring method are drawn together. As can be inferred, the general mechanism of lining behavior is obtained similar in two different methods but there are some differences in values of moment. These differences can be caused by instrumentations errors, simplified of numerical models, laboratories mistakes and so on. It can be seen in Figure 9, the extreme values of bending moment are at the bottom corner of the canal, in the intersection point of the wall and the canal floor and also in mid-height of canal section.

According to Figure 9, analysis results show that, 16 days after the impounding, the resulted moments in some part of side wall are greater than cracking moment and concrete lining will crack in these locations. Also as seen in Figure 9, the bending moments are equal to zero in joint locations. So joints have vital rules to control and distribute of destructive moments. Therefore, by embedding only one joint in canal wall, damage of canal lining cannot be prevented. With considering all obtained results, another series of joints is embedded in canal wall in Test 3 and the effect of it is studied by physical and numerical models.

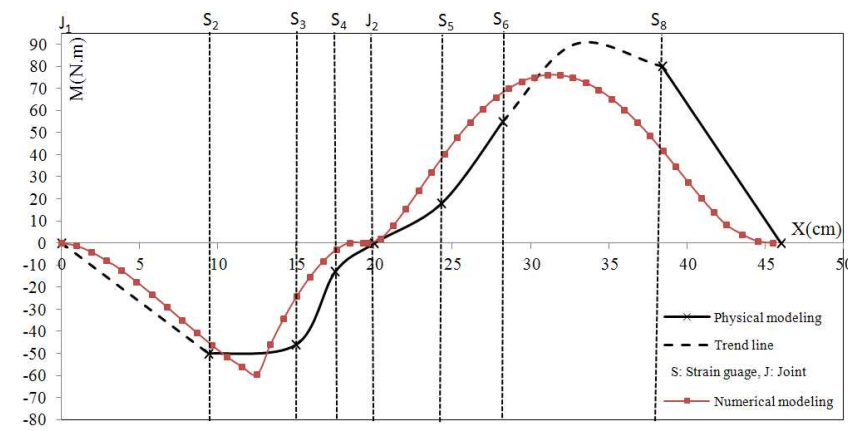

Fig 9. Bending moment of lining in Test 2 obtained from numerical and physical modeling

\subsection{Test 3}

In this test, two series of joints are embedded in canal wall. They are considered $5 \mathrm{~cm}$ and $12.5 \mathrm{~cm}$ above the floor, respectively. Since in Test 3, the specifications of bed soil are same as Test 2, the horizontal and vertical displacement vectors are similar in them and the magnitude of displacement are approximately equal. But the concentration of contours around the joints has been eliminated in current test. It represents the significant reduction of relative displacement between two panels of canal wall. Thus the efficiency of joints to control of panels behavior is clarified.

In Test 3 and by considering additional joints, the relative displacement between two panels is reached to $0.1 \mathrm{~mm}$. This reduction is led to decreasing the interaction pressure between two panels and ultimately fragmentation in this zone is minimized. In addition the maximum value of volumetric and shear strains are reached to $3 \%$ and $0.15 \%$ in Test 3 , respectively.

The strain values are not significantly changed in Test 3 in compared with Test 2 but the distinction point of them is that the concentration of strain curves has been eliminated in Test 3. It has happened because of the considering second series of joint in canal section. This phenomenon emphasizes the effect of joints to control the deformed shape of lining and relative displacement of panels. To compare the results of monitoring and study the effect of considering additional joint on destructive moments, the bending moment of lining in Test 2 and 3 are given together in Figure 10. As seen in this curves, considering additional joint led to significant reduction of bending moment in canal wall. This reduction is strongly 
impressive and can prevent canal lining cracking. It is inferred that the lining among points $\mathrm{J} 1-\mathrm{J} 2, \mathrm{~J} 2$ - J3 and J3- end point of canal section acts independently. If the closed distance between two points is chosen, the less moment will be caused. Therefore, the number and location of joints should be optimized based on the properties of soil and geometric characteristics of a canal section. By referring to results, in recent model and Tabriz plain canal, considering two series of joints on canal wall seems necessary.

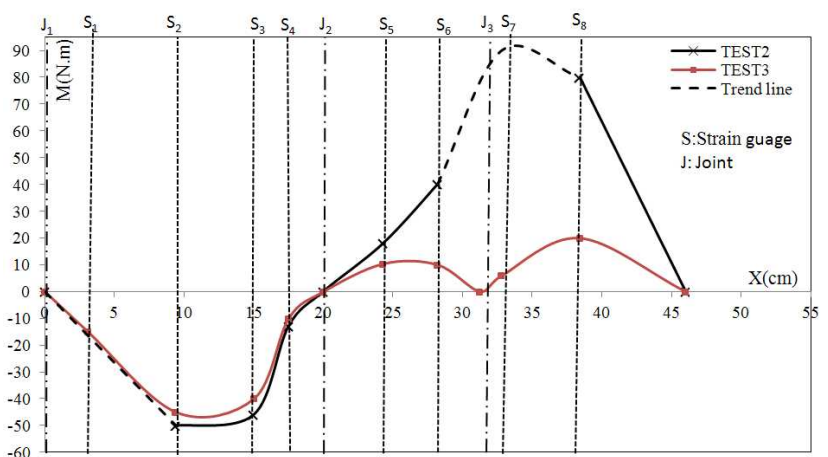

Fig10. Bending moment of canal lining in Test 3

Test 3 is also studied by numerical modeling. The maximum value of soil swelling is calculated about $4.55 \mathrm{~mm}$ in numerical model. This value is recorded about $4.5 \mathrm{~mm}$ from physical model. The obtained results from numerical modeling of Test 3 show that by considering an additional joint on canal wall, the relative displacement of panels is impressively reduced whereas the total value of soil heave has not significantly changed in compared with Test 2.

In Figure 11, the bending moment of lining that obtained from numerical modeling and strain gauges records are given together. As inferred from this figure, the results are quite similar. Also in this figure, the effect of additional joint series (J3) to control and reduce of bending moment on lining is clearly seen.

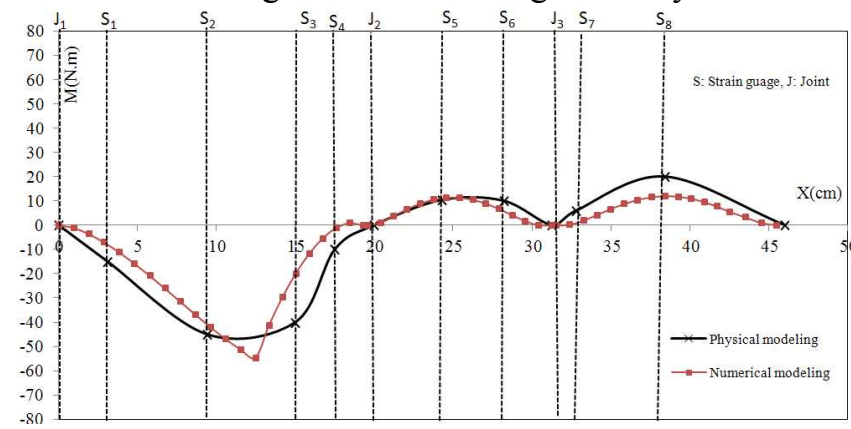

Fig11. Bending moment curves that obtained from numerical and physical modeling in Test3

\section{CONCLUSION}

The results of this study show that the vertical displacement is dominant in compare with horizontal displacement in canal bed soil and interaction points of soil and lining are locus of maximum displacement values. In the other hand, the volumetric strains of soil mass are obtained greater than shear strains. This means that volume change of soil is dominated to deformation of it. The displacement and volumetric strain contours show that the value and concentration of these contours are reached to maximum value around the mid height of canal section. It implies the existence of maximum value of interaction forces in this zone. Developed cracks in this zone of canal lining that has been observed in site investigations confirmed obtained results. By embedding additional joint in this critical zone, the destructive forces can be controlled. This suggestion way has been examined in this paper. The obtained results from numerical and physical models indicate that the joints along the wall act as a hinge, the values of moment in these points are zero and they have a functional role to control the cracking in the canal wall. So, optimization of number and location of joints in canal section is significant way to reduce the lining damage in canals which are constructed on expansive soils. In general and for current case, considering two series of joints are recommended in both walls of the canal section, first series near the canal floor, the intersection point of wall and floor, and second series about middle height of canal section, the concentration point of interaction forces.

\section{REFERENCES}

Chen, F.H. (1988): Foundations on Expansive Soils, Elsevier Scientific Publishing Co., Amsterdam.

Fredlund, D. G. and Raharadjo, H. (1993): Soil Mechanics for Unsaturated Soils, John Wiley \&Sons. New York.

Fredlund, D. G. (2000). The 1999 R.M. Hardly Lecture: The implementation of unsaturated soil mechanics into geotechnical engineering, Canadian Geotechnical Journal. 37(5):963-986.

GEO-SLOPE finite element analysis user's manual. (2008): Stress-Deformation Modeling with SIGMA/W 2007, Third edition Calgary, Alberta, Canada.

Hajialilue-Bonab, M., Behroozsarand, F. and Cheshmdost, M. (2009):The effect of bed soil swelling on Tabriz Plain canal and proposed a correction method, Journal of Iranian association of engineering geology, vol.2, No. 1\&2, pp.83-98.

Hung, Q., Vu and Fredlund, D. G. (2006): Challenges to modeling heave to expansive soils, Canadian Geotechnical Journal.43 (12): $1240-1272$

.Rao, A.S., Phanikumar B.R. and Sharma, R.S. (2004): Prediction of swelling characteristics of remoulded and compacted expansive soils using free swell index, The Quarterly Journal of Engineering Geology and Hydrogeology, Vol. 37, No. 3, pp. 217-226.

Sharma, R.S. (1998): Mechanical behavior of unsaturated highly expansive clays, D.Phil. (Doctor of Philosophy) thesis, University of Oxford, England.

Take, W.A. (2003): The influence of seasonal moisture cycles on clay slopes, PhD thesis, University of Cambridge, UK.

Vu, H.Q. and Fredlund, D. G. (2004): The prediction of one, two and three-dimensional heave in expansive soils, Canadian Geotechnical Journal, 41:713-737.

White, D.J., Take, W.A. and Bolton, M.D. (2003): Soil deformation measurement using particle image velocimetry (PIV) and photogrammetry, Geotechnique, 53(7), 619-631. 